\title{
CARACTERIZAÇÃo FÍSICA E DE PRODUÇÃO DE ACEROLA DO BANCO ATIVO DE GERMOPLASMA EM PERNAMBUCO ${ }^{1}$
}

\author{
ROSIMAR DOS SANTOS MUSSER ${ }^{2}$, MARGARIDA AGOSTINHO LEMOS ${ }^{3}$, VERA LÚCIA ARROXELAS GALVÃO DE \\ LIMA $^{4}$, ENAYDE DE ALMEIDA MÉLO ${ }^{5}$, ILDO ELIEZER LEDERMAN ${ }^{6}$, VENÉZIO FELIPE DOS SANTOS 7
}

\begin{abstract}
RESUMO - Este trabalho teve por objetivo avaliar as características físicas dos frutos e a produção de doze genótipos de aceroleiras do Banco Ativo de Germoplasma da Universidade Federal Rural de Pernambuco. Frutos colhidos nas safras Inverno/1999, Verão/2000 e Verão/2001 foram avaliados quanto a massa, altura e diâmetro médio, bem como as características de produção e o número médio de frutos/genótipo. A análise conjunta (média das safras) revelou uma variação média na massa de 3,88 a 7,11g, na altura de 1,74 a 2,07cm e no diâmetro de 1,94 a 2,46cm. A variação na produção anual dos 12 genótipos, no ano de 1999, compreendeu valores entre 3,23 e 10,31kg de fruto/planta, enquanto no ano de 2000 esta variação foi de 6,73 a 44,70kg de fruto/planta. Nos anos de 1999 e 2000, cerca de 50\% da produção anual ficou concentrada nos meses de outubro, novembro e dezembro. Os genótipos 012-CPA, 013-CPA e 014-CPA destacaram-se como potencialmente promissores por terem sido os mais produtivos além de terem apresentado características físicas, referentes à massa e do diâmetro dos frutos, exigidas pelas indústrias de transformação.
\end{abstract}

Termos para indexação: Malpighia emarginata D.C., cereja-das-Antilhas, qualidade dos frutos.

\section{PHYSICAL AND PRODUCTION CHARACTERISTICS OF ACEROLA FRUIT FROM ACTIVE GERMPLASM BANK IN PERNAMBUCO}

\begin{abstract}
The objective of this research was to evaluate the physical and production characteristics of fruits from twelve acerola genotypes cultivated at the Active Germplasm Bank in Federal Rural University of Pernambuco. The average weight and size of fruits from the Winter/1999, Summer/2000 and Summer/2001 seasons as well as plant yield and average number of fruits/genotype were assessed. Results from the joint analysis of all harvests presented average variation on fruit weight of 3.88 to $7.11 \mathrm{~g}$; fruit height of 1.74 to $2.07 \mathrm{~cm}$ and fruit diameter of 1.94 to $2.46 \mathrm{~cm}$. The annual production variation of 12 genotypes during 1999 was of 3.23 to $10.31 \mathrm{Kg}$ of fruit/plant; meanwhile during 2000 this variation was of 6.73 to.44.70 Kg of fruit/plant. In 1999 and 2000, approximately, 50\% of the annual production occurred in October, November and December. The genotypes 012-CPA, 013-CPA and 014-CPA are potentially promising because they were considered the most productive and showed the physical characteristics (weight and diameter) demanded by transformation industry.
\end{abstract}

Index terms: Malpighia emarginata D.C., Barbados cherry, fruits quality.

A dimensão do fruto de acerola é uma característica física relevante na seleção de variedades comerciais. Quanto maior o fruto, mais fácil e rápida é sua colheita, demandando menos mão-de-obra e, conseqüentemente, reduzindo os custos de produção. Entretanto, essa característica deve ser acompanhada de outros parâmetros de qualidade, como: teor de vitamina $\mathrm{C}$, cor, textura, além do número de frutos/planta e massa média dos frutos, entre outros. Dentre os vários fatores que influenciam nestas características, destacam-se aqueles relacionados a clones, pluviosidade, aplicação de fertilizantes e irrigação (Gonzaga Neto et al., 1999).

Comumente, frutos de acerola apresentam comprimento de 1 a $3 \mathrm{~cm}$, diâmetro de $1 \mathrm{a} 4 \mathrm{~cm}$ e massa de 2 a $16 \mathrm{~g}$ (Gonzaga Neto \& Soares, 1994; Gorgatti Netto et al., 1996). Os frutos das cultivares UEL3Dominga, UEL4-Lígia e UEL5-Natália apresentaram massa média de $6,31 \mathrm{~g}, 7,85 \mathrm{~g}$ e 7,47g, respectivamente (Carpentieri-Pípolo et al., 2002). Em 18 genótipos de aceroleira do Centro de Pesquisa Agropecuária do Trópico Semi-Árido, Região do Submédio São Francisco, foram encontrados frutos com massa média de 2,85 a $6,90 \mathrm{~g}$. A produção anual desses genótipos $(17,51$ a $179,21 \mathrm{~kg}$ de frutos/planta) foi considerada uma característica promissora tendo em vista que em plantios comerciais a produção média varia de 3 a $30 \mathrm{~kg} /$ planta/ano. De modo geral, os genótipos com maior produção apresentaram menor massa média de frutos (Gonzaga Neto et al., 1999). Aceroleiras cultivadas na Paraíba também apresentaram variação na produção $(2,01$ a 27,10kg/planta/ano) (Batista et al., 1991).

Visando a selecionar plantas de interesse agronômico para a
Zona da Mata de Pernambuco como copa produtora, este trabalho teve por objetivo avaliar as características físicas dos frutos e a produção de 12 genótipos de aceroleiras do Banco Ativo de Germoplasma da Universidade Federal Rural de Pernambuco.

O Banco Ativo de Germoplasma (BAG) de aceroleiras, implantado em junho de 1998, foi instalado na Estação Experimental de Cana-de-Açúcar do Carpina (E.E.C.A.C./UFRPE), município de Carpina$\mathrm{PE}$, latitude $7^{\circ} 51^{\prime} 04$ ', longitude $35^{\circ} 14^{\prime} 27^{\prime}$ ' $\mathrm{W}$, a $178 \mathrm{~m}$ de altitude, onde, segundo a classificação de Köppen, predomina o tipo climático "AS" tropical chuvoso com verão seco. A temperatura e a precipitação pluvial média, durante o período deste estudo, foram de $25,98^{\circ} \mathrm{C}$ e $122,56 \mathrm{~mm} /$ mês, respectivamente. As mudas, originárias de estacas semilenhosas, foram introduzidas no BAG com cinco meses de idade, sendo, portanto, instalados 12 genótipos cognominados de 002-SPE, 003-APE, 004-RPE, 005-APE, 006-TPA, 007-TPA, 008-CPA, 011-BPA, 012-CPA, 013-CPA, 014-CPA e 015-CPA. O delineamento experimental foi instalado em blocos completamente casualizados (cinco blocos), com doze tratamentos (doze genótipos), tendo uma planta por parcela, em espaçamento $5 \times 4 \mathrm{~m}$, totalizando 60 plantas, sobre o solo do tipo Argissolo. Foram realizados, periodicamente, tratos culturais referentes a capinas, adubação (adubo $\mathrm{N}, \mathrm{P}, \mathrm{K}$, tendo como fonte uréia, superfosfato triplo e cloreto de potássio, respectivamente), controle fitossanitário, podas de limpeza e irrigação, com turno de rega, em média, de $2 \mathrm{~h} /$ dia.

No Laboratório de Química da E.E.C.A.C, diariamente, foram efetuadas a pesagem e a contagem ( $\mathrm{kg}$ e $\mathrm{n}^{\mathrm{o}}$ de frutos/genótipo) dos frutos para a obtenção dos dados de produção na fase juvenil das

\footnotetext{
${ }^{1}$ (Trabalho 171/2004). Recebido: 28/11/2004. Aceito para publicação: 22/08/2005. Parte da Tese de Doutorado da primeira autora apresentada ao Programa de PósGraduação em Botânica (PPGB) da Universidade Federal Rural de Pernambuco (UFRPE), executada com apoio da PPGB/UFRPE.

${ }^{2}$ Eng. Agr., Doutor, Prof A Adjunto do Depto. de Agronomia da UFRPE, Av. Dom Manoel de Medeiros s/n, CEP: 52171-900, PE, E-mail: rmusser@ufrpe.br Autor para correspondência.

${ }^{3}$ Eng. Agr., Doutor, Professora Adjunto da UFRPE.

${ }^{4}$ Eng. Químico, Mestre, Professora Adjunto da UFRPE.

${ }^{5}$ Nutricionista, Doutor, Professora Adjunto da UFRPE.

${ }^{6}$ Eng. Agr., PhD, Pesquisador da Empresa Pernambucana de Pesquisa Agropecuária-IPA, Caixa Postal: 1022. Recife-PE.

${ }^{7}$ Eng. Agr., Pesquisador da Empresa Pernambucana de Pesquisa Agropecuária-IPA.
} 
plantas, tendo em vista a necessidade de avaliar o tamanho do fruto e a capacidade real de produção de cada genótipo. Nas safras que coincidiram com a estação úmida (Inverno-agosto-setembro/1999) e seca (Verão-fevereiro/2000 e março/2001), amostras, contendo até 50 frutos maduros de cada parcela do experimento, foram utilizadas para a determinação da massa, do comprimento e do diâmetro.

Para a análise estatística, os dados originais referentes à produção e ao número médio de frutos foram transformados em Ln $(\mathrm{x}+1)$ e submetidos ao programa GENES, versão 1.0 - Embrapa (Cruz, 1997). Os resultados da safra de 1999 foram submetidos ao programa NTIA, versão 4.2.1 (EMBRAPA, 1996) e os das demais safras, ao programa GENES, versão 1.0 - Embrapa (Cruz, 1997), sendo as médias comparadas pelo teste "SNK" (Stundent-Newman-Keuls), ao nível de $5 \%$ de probabilidade.

TABELA 1 - Massa média (g) de frutos de acerolas provenientes do Banco Ativo de Germoplasma da Universidade Federal Rural de Pernambuco (BAG /UFRPE) colhidas em diferentes safras.

\begin{tabular}{|c|c|c|c|c|}
\hline \multirow{2}{*}{$\begin{array}{l}\text { Genótipos } \\
\text { (Código) }\end{array}$} & \multicolumn{4}{|c|}{ Safras } \\
\hline & Inverno 1999 & Verão 2000 & Verão 2001 & Média \\
\hline 002-SPE & $5,25 \mathrm{ab}$ & $6,13 \mathrm{a}$ & $9,39 \mathrm{abc}$ & $6,75 \mathrm{a}$ \\
\hline 003-APE & $5,06 \mathrm{ab}$ & $6,04 \mathrm{a}$ & $9,38 \mathrm{abc}$ & $6,64 \mathrm{a}$ \\
\hline 004-RPE & $4,52 \mathrm{ab}$ & $5,23 \mathrm{abc}$ & $10,62 \mathrm{ab}$ & $6,95 \mathrm{a}$ \\
\hline 005-APE & $3,95 \mathrm{ab}$ & $3,17 \mathrm{~d}$ & $5,24 \mathrm{~g}$ & $4,12 \mathrm{e}$ \\
\hline 006-ТРА & $5,83 \mathrm{a}$ & $4,33 \mathrm{bcd}$ & $11,17 \mathrm{a}$ & $7,11 \mathrm{a}$ \\
\hline 007-ТPA & $5,73 \mathrm{a}$ & $3,59 \mathrm{~cd}$ & $6,08 \mathrm{fg}$ & $5,13 \mathrm{c}$ \\
\hline 008-СРА & $5,60 \mathrm{a}$ & $5,81 \mathrm{ab}$ & $9,02 \mathrm{bcd}$ & $6,81 \mathrm{a}$ \\
\hline 011-BPA & $3,87 \mathrm{ab}$ & $3,49 \mathrm{~cd}$ & $7,27 \mathrm{def}$ & $4,88 \mathrm{~cd}$ \\
\hline 012-CPA & $3,90 \mathrm{ab}$ & $4,12 \mathrm{~cd}$ & $6,75 \mathrm{efg}$ & $4,92 \mathrm{~cd}$ \\
\hline 013-СРА & $2,94 \mathrm{~b}$ & $3,09 \mathrm{~d}$ & $6,03 \mathrm{fg}$ & $3,88 \mathrm{e}$ \\
\hline 014-СРА & $4,18 \mathrm{ab}$ & $3,90 \mathrm{~cd}$ & $9,11 \mathrm{bcd}$ & $5,73 \mathrm{bc}$ \\
\hline 015-СРА & $5,97 \mathrm{a}$ & $5,00 a b c$ & 8,26 cde & $6,41 \mathrm{ab}$ \\
\hline Média & 4,74 & 4,49 & 8,19 & 5,78 \\
\hline L.sup ${ }^{1}$ & 5,365 & 5,199 & 9,402 & 6,502 \\
\hline L.inf ${ }^{1}$ & 4,113 & 3,783 & 6,982 & 5,044 \\
\hline c.v $(\%)^{2}$ & 24,53 & 20,04 & 13,13 & 16,65 \\
\hline
\end{tabular}

Médias seguidas da mesma letra na coluna não diferem significativamente pelo teste de Student-Newman-Keuls (SNK), em nível de 5\% de probabilidade.

${ }^{1}$ Intervalo de confiança da média com $95 \%$ de probabilidade, limites superior e inferior.

${ }^{2}$ Coeficiente de variação.
A massa média dos frutos variou de $3,88 \mathrm{~g}$ a $7,11 \mathrm{~g}$, cujos valores mais elevados foram apresentados pelos frutos dos genótipos 006TPA, 004-RPE, 008-CPA, 002-SPE, 003-APE e 015-CPA (Tabela 1). Os frutos dos genótipos 005-APE, 011-BPA, 012-CPA e 013-CPA, na primeira safra (Inverno/1999), bem com os dos genótipos 005-APE, 007-TPA, 011-BPA, 013-CPA e 014-CPA, na segunda safra (Verão/2000), não atingiram a massa mínima de $4 \mathrm{~g} /$ fruto, exigida pelas indústrias de transformação (IBRAF, 1995). Entretanto, na terceira safra (Verão/2001), todos os genótipos apresentaram frutos com massa superior a $4 \mathrm{~g}$.

O comprimento e o diâmetro médio dos frutos mostraram variações significativas entre os genótipos (Tabela 2). A análise desses parâmetros indica que os frutos são, em média, mais largos que altos, variando de $1,74 \mathrm{~cm}$ a $2,07 \mathrm{~cm}$ no comprimento, e de $1,94 \mathrm{~cm}$ a $2,46 \mathrm{~cm}$ no diâmetro, o que define um formato, em geral, subgloboso. Essas variações encontram-se dentro das faixas de tamanho citadas por Gorgatti Netto et al. (1996). O Instituto Brasileiro de Frutas (IBRAF, 1995), dentre os critérios de qualidade estabelecidos para acerola, indica que os frutos para serem aceitos pelas indústrias de transformação devem ter diâmetro mínimo de $1,5 \mathrm{~cm}$. Embora todos os genótipos estudados tenham superado esse padrão, os genótipos 002-SPE, 003APE, 004-RPE, 006-TPA, 008-CPA e 015-CPA destacaram-se por terem apresentado diâmetro mais elevado $(\mathrm{p}<0,05)$.

A produção média dos genótipos, embora tenha sido avaliada desde a instalação do BAG, foi considerada, para efeito de análise estatística, e os dados coletados a partir de janeiro/99, tendo em vista que todos os genótipos se encontravam em produção. Contudo, vale ressaltar que a produção dos genótipos mais precoces (014-CPA, 013CPA, 011-BPA, 012-CPA e 007-TPA) teve início em setembro/98, três meses após o plantio das mudas. A produção dos genótipos de aceroleira da EMBRAPA-CPATSA/Petrolina-PE foi também precoce, com o início da produção ocorrendo quatro meses após o plantio (Gonzaga Neto et al., 1999).

A distribuição da produção anual concentrou-se no $4^{\circ}$ trimestre dos anos de 1999 e 2000 (Tabela 3). Nesse período, ocorreu elevação da temperatura e da insolação, cuja média registrada no mês de outubro foi de $25,3^{\circ} \mathrm{C}$ e $269,65 \mathrm{~h} / \mathrm{mês}$ e no mês de dezembro de $26,3^{\circ} \mathrm{C}$ e $244,25 \mathrm{~h} / \mathrm{mês}$, respectivamente. Redução na produção dos genótipos foi observada no $3^{\circ}$ trimestre/2000, exceto para os genótipos 011-BPA e 014-CPA, período caracterizado por redução da insolação $(178,50 \mathrm{~h} / \mathrm{mês})$ e aumento da pluviosidade $(273,57 \mathrm{~mm} / \mathrm{mês})$. A análise dos dados permite inferir que a produção foi influenciada principalmente por esses fatores

TABELA 2 - Comprimento e diâmetro de frutos de acerolas provenientes do Banco Ativo de Germoplasma da Universidade Federal Rural de Pernambuco (BAG/UFRPE) colhidas em diferentes safras.

\begin{tabular}{|c|c|c|c|c|c|c|c|c|}
\hline \multirow{3}{*}{$\begin{array}{l}\text { Genótipos } \\
\text { (Código) }\end{array}$} & \multicolumn{8}{|c|}{ Safras } \\
\hline & \multicolumn{2}{|c|}{ Inverno 1999} & \multicolumn{2}{|c|}{ Verão 2000} & \multicolumn{2}{|c|}{ Verão 2001} & \multicolumn{2}{|c|}{ Média } \\
\hline & $\begin{array}{c}\text { Comp. } \\
\text { (cm) }\end{array}$ & $\begin{array}{c}\text { Diâmetro } \\
\text { (cm) }\end{array}$ & $\begin{array}{l}\text { Comp. } \\
(\mathrm{cm})\end{array}$ & $\begin{array}{c}\text { Diâmetro } \\
\text { (cm) }\end{array}$ & $\begin{array}{c}\text { Comp. } \\
(\mathrm{cm})\end{array}$ & Diâmetro (cm) & $\begin{array}{c}\text { Comp. } \\
\text { (cm) }\end{array}$ & $\begin{array}{c}\text { Diâmetro } \\
\text { (cm) }\end{array}$ \\
\hline 002-SPE & $1,90 \mathrm{a}$ & $2,21 \mathrm{a}$ & $1,88 \mathrm{ab}$ & $2,31 \mathrm{a}$ & $2,31 \mathrm{abc}$ & $2,72 \mathrm{bc}$ & $2,01 \mathrm{abc}$ & $2,39 \mathrm{a}$ \\
\hline 003-APE & $1,84 \mathrm{ab}$ & $2,12 \mathrm{ab}$ & $1,96 \mathrm{a}$ & $2,29 \mathrm{a}$ & $2,36 \mathrm{ab}$ & $2,69 \mathrm{bc}$ & $2,03 \mathrm{abc}$ & $2,36 \mathrm{a}$ \\
\hline 004-RPE & $1,89 \mathrm{a}$ & $2,13 \mathrm{ab}$ & $1,92 \mathrm{ab}$ & $2,23 \mathrm{ab}$ & $2,36 \mathrm{ab}$ & $2,84 \mathrm{ab}$ & $2,07 \mathrm{a}$ & $2,42 \mathrm{a}$ \\
\hline 005-APE & $1,82 \mathrm{ab}$ & $1,99 \mathrm{ab}$ & $1,65 \mathrm{~cd}$ & $1,85 \mathrm{~d}$ & $2,09 \mathrm{~d}$ & $2,31 \mathrm{e}$ & $1,85 \mathrm{~d}$ & $2,05 \mathrm{c}$ \\
\hline 006-TPA & $1,95 \mathrm{a}$ & $2,34 \mathrm{a}$ & $1,78 \mathrm{abcd}$ & 2,06 abcd & $2,42 \mathrm{a}$ & $2,99 \mathrm{a}$ & $2,05 \mathrm{ab}$ & $2,46 \mathrm{a}$ \\
\hline 007-TPA & $1,98 \mathrm{a}$ & $2,29 \mathrm{a}$ & $1,65 \mathrm{~cd}$ & $1,93 \mathrm{~cd}$ & $2,11 \mathrm{~cd}$ & $2,34 \mathrm{e}$ & $1,91 \mathrm{~cd}$ & $2,19 \mathrm{~b}$ \\
\hline 008-CPA & $1,94 \mathrm{a}$ & $2,24 \mathrm{a}$ & $1,91 \mathrm{ab}$ & $2,26 \mathrm{ab}$ & $2,30 \mathrm{abc}$ & $2,63 \mathrm{bcd}$ & $2,05 \mathrm{ab}$ & $2,38 \mathrm{a}$ \\
\hline 011-BPA & $1,70 \mathrm{ab}$ & $2,05 \mathrm{ab}$ & $1,59 \mathrm{~d}$ & $2,02 \mathrm{bcd}$ & $2,17 \mathrm{bcd}$ & $2,46 \mathrm{de}$ & $1,82 \mathrm{de}$ & $2,18 b$ \\
\hline 012-CPA & $1,73 \mathrm{ab}$ & $1,98 \mathrm{ab}$ & $1,73 \mathrm{bcd}$ & $1,96 \mathrm{~cd}$ & $2,27 \mathrm{abcd}$ & $2,37 \mathrm{e}$ & $1,91 \mathrm{~cd}$ & $2,10 \mathrm{bc}$ \\
\hline 013-CPA & $1,58 \mathrm{~b}$ & $1,79 \mathrm{~b}$ & $1,58 \mathrm{~d}$ & $1,80 \mathrm{~d}$ & $2,12 \mathrm{~cd}$ & $2,29 \mathrm{e}$ & $1,74 \mathrm{e}$ & $1,94 \mathrm{~d}$ \\
\hline 014-CPA & $1,78 \mathrm{ab}$ & $2,04 \mathrm{ab}$ & $1,718 \mathrm{bcd}$ & $1,95 \mathrm{~cd}$ & $2,31 \mathrm{abc}$ & $2,67 \mathrm{bc}$ & $1,93 \mathrm{bcd}$ & $2,22 \mathrm{~b}$ \\
\hline 015-CPA & $1,95 \mathrm{a}$ & $2,31 \mathrm{a}$ & 1,83 abc & $2,15 \mathrm{abc}$ & $2,30 \mathrm{abc}$ & $2,59 \mathrm{~cd}$ & $2,03 \mathrm{abc}$ & $2,35 \mathrm{a}$ \\
\hline Média & 1,84 & 2,13 & 1,77 & 2,07 & 2,26 & 2,58 & 1,95 & 2,25 \\
\hline L.sup ${ }^{1}$ & 1,915 & 2,223 & 1,852 & 2,180 & 2,331 & 2,719 & 2,017 & 2,356 \\
\hline L.inf ${ }^{1}$ & 1,759 & 2,022 & 1,682 & 1,956 & 2,191 & 2,435 & 1,883 & 2,148 \\
\hline c.v $(\%)^{2}$ & 8,38 & 8,61 & 6,27 & 6,67 & 4,41 & 4,73 & 6,15 & 6,12 \\
\hline
\end{tabular}

Médias seguidas da mesma letra na coluna não diferem significativamente pelo teste de Student-Newman-Keuls (SNK), em nível de 5\% de probabilidade.

${ }^{1}$ Intervalo de confiança da média com $95 \%$ de probabilidade, limites superior e inferior.

${ }^{2}$ Coeficiente de variação. 
TABELA 3 - Distribuição da produção e número de safras em 1999 e em 2000 de aceroleiras do Banco Ativo de Germoplasma da Universidade Federal Rural de Pernambuco (BAG/UFRPE).

\begin{tabular}{|c|c|c|c|c|c|c|}
\hline \multirow{2}{*}{$\begin{array}{l}\text { Genótipos } \\
\text { (Código) }\end{array}$} & \multirow{2}{*}{$\begin{array}{c}\text { PA } \\
\text { (Kg/planta) }\end{array}$} & \multicolumn{4}{|c|}{ Produção Trimestral (\%) } & \multirow{2}{*}{ NSA } \\
\hline & & $\mathbf{1}^{\mathrm{o}}$ & $2^{\circ}$ & $3^{0}$ & $4^{0}$ & \\
\hline \multicolumn{7}{|c|}{ Ano de 1999} \\
\hline 002-SPE & 5,952 & 11,46 & 22,82 & 19,42 & 46,30 & 6 \\
\hline 003-APE & 4,859 & 18,85 & 22,39 & 5,97 & 52,79 & 5 \\
\hline 004-RPE & 5,564 & 18,60 & 18,64 & 17,83 & 44,93 & 5 \\
\hline 005-APE & 3,234 & 8,91 & 16,39 & 10,30 & 64,41 & 2 \\
\hline 006-TPA & 5,304 & 12,20 & 22,15 & 13,31 & 52,34 & 4 \\
\hline 007-TPA & 7,585 & 14,24 & 15,94 & 17,48 & 52,34 & 5 \\
\hline 008-CPA & 6,015 & 9,19 & 24,66 & 16,38 & 49,78 & 4 \\
\hline 011-BPA & 5,665 & 8,86 & 24,77 & 27,27 & 39,10 & 6 \\
\hline 012-CPA & 9,029 & 10,62 & 18,85 & 22,83 & 47,70 & 4 \\
\hline 013-CPA & 10,310 & 14,55 & 23,01 & 20,46 & 41,99 & 5 \\
\hline 014-CPA & 8,476 & 9,80 & 23,71 & 23,27 & 43,22 & 6 \\
\hline 015-CPA & 6,401 & 12,45 & 24,25 & 14,08 & 49,23 & 7 \\
\hline Média & 6,533 & 12,48 & 21,47 & 17,38 & 48,68 & 4,92 \\
\hline \multicolumn{7}{|c|}{ Ano de 2000} \\
\hline 002-SPE & 21,545 & 23,33 & 16,12 & 5,84 & 54,71 & 5 \\
\hline 003-APE & 16,312 & 33,31 & 20,98 & 5,15 & 40,56 & 5 \\
\hline 004-RPE & 22,567 & 20,76 & 21,20 & 10,50 & 47,54 & 4 \\
\hline 005-APE & 6,725 & 28,46 & 4,15 & 1,75 & 65,64 & 4 \\
\hline 006-ТРA & 22,317 & 13,42 & 19,75 & 12,77 & 54,06 & 5 \\
\hline 007-TPA & 19,802 & 23,15 & 16,65 & 1,93 & 58,25 & 4 \\
\hline 008-CPA & 17,933 & 9,65 & 6,71 & 5,42 & 78,22 & 4 \\
\hline 011-BPA & 20,378 & 15,79 & 7,60 & 14,33 & 62,29 & 4 \\
\hline 012-CPA & 38,767 & 10,28 & 19,74 & 18,32 & 51,66 & 5 \\
\hline 013-СРA & 32,190 & 19,24 & 21,09 & 12,21 & 47,46 & 5 \\
\hline 014-СРА & 44,695 & 12,82 & 19,39 & 19,97 & 47,83 & 5 \\
\hline 015-CРA & 26,243 & 19,54 & 19,17 & 8,49 & 52,79 & 5 \\
\hline Média & 24,123 & 19,15 & 16,05 & 9,72 & 55,08 & 4,58 \\
\hline
\end{tabular}

PA: Produção anual; NSA: Número de safras anual.

climáticos, considerando que, fisiologicamente, estimulam a fotossíntese. Esse comportamento era de se esperar, tendo em vista que a aceroleira é uma planta tropical e subtropical (Marino Netto, 1986).

O número de safras, caracterizado pela produção mensal de cada genótipo, variou, no ano de 1999, de 2 a 7 safras, enquanto, em 2000, com produção mais uniforme, esse número variou de 4 a 5 . Existe,

TABELA 4- Número médio de frutos/genótipo/ano de aceroleiras do Banco Ativo de Germoplasma da Universidade Federal Rural de Pernambuco (BAG/UFRPE) ${ }^{1}$

\begin{tabular}{|c|c|c|c|c|}
\hline \multirow{2}{*}{$\begin{array}{l}\text { Genótipos } \\
\text { (Código) }\end{array}$} & \multicolumn{4}{|c|}{ Ano } \\
\hline & 1999 & 2000 & 2001 & Média \\
\hline 002-SPE & $231 \mathrm{c}$ & $372 \mathrm{~d}$ & 458 ef & $354 \mathrm{~cd}$ \\
\hline 003-APE & $194 \mathrm{c}$ & $320 \mathrm{~d}$ & $739 \mathrm{def}$ & $417 \mathrm{bcd}$ \\
\hline 004-RPE & $173 \mathrm{c}$ & $430 \mathrm{~cd}$ & $375 \mathrm{f}$ & $326 \mathrm{~cd}$ \\
\hline 005-APE & $149 \mathrm{c}$ & $167 \mathrm{e}$ & $376 \mathrm{f}$ & $231 \mathrm{~d}$ \\
\hline 006-ТPA & $187 \mathrm{c}$ & $370 \mathrm{~d}$ & 1053 bcde & $537 \mathrm{abcd}$ \\
\hline 007-ТРА & $322 a b c$ & $491 \mathrm{bc}$ & 797 cdef & $537 \mathrm{abcd}$ \\
\hline 008-СРА & $256 a b c$ & $365 \mathrm{~d}$ & 711 ef & $444 \mathrm{bcd}$ \\
\hline 011-BPA & $395 \mathrm{ab}$ & $472 \mathrm{~cd}$ & $1264 a b$ & $710 \mathrm{ab}$ \\
\hline 012-CPA & $372 a b$ & $840 a b$ & $1024 \mathrm{cdef}$ & $745 \mathrm{ab}$ \\
\hline 013-СРА & $517 \mathrm{a}$ & $773 \mathrm{abc}$ & $1377 \mathrm{a}$ & $889 \mathrm{a}$ \\
\hline 014-CPA & $308 a b c$ & $917 \mathrm{a}$ & $1245 \mathrm{abc}$ & $823 \mathrm{a}$ \\
\hline 015-СРА & $236 \mathrm{bc}$ & $468 \mathrm{~cd}$ & $1112 \mathrm{abcd}$ & $606 \mathrm{abc}$ \\
\hline Média & 278 & 499 & 878 & 552 \\
\hline L.sup ${ }^{2}$ & 348 & 643 & 1102 & 684 \\
\hline L.inf ${ }^{2}$ & 209 & 355 & 653 & 419 \\
\hline c.v $(\%)^{3}$ & 38,34 & 32,48 & 20,25 & 56,90 \\
\hline
\end{tabular}

${ }^{1}$ Para a análise da variância, foi feita a transformação dos dados em $\operatorname{Ln}(\mathrm{x}+1)$ Médias originais seguidas da mesma letra na cada coluna não diferem significativamente, pelo teste "SNK", em nível de 5\% de probabilidade.

${ }^{2}$ Intervalo de confiança da média original com $95 \%$ de probabilidade, limites superior e inferior.

${ }^{3}$ Coeficiente de variação. portanto, a necessidade de continuar esse monitoramento até que seja constatada a estabilização da produção e, conseqüentemente, do número de safras na região onde está localizado o BAG. Essa informação auxiliará o futuro planejamento das safras, por ocasião da indicação de genótipos promissores para plantio, aliada aos dados climatológicos.

Nos anos de 1999 e de 2000, os genótipos 012-CPA, 013-CPA e 014-CPA destacaram-se por terem sido os mais produtivos. As variações na produção anual dos 12 genótipos, no ano de 1999, compreenderam valores entre 3,23 e 10,31 kg de fruto/planta, enquanto, no ano de 2000, essa variação foi de 6,73 a 44,70kg de fruto/planta (Tabela 3). Nesse ano, os genótipos acima citados apresentaram produção de frutos superior ao das cultivares UEL3-Dominga, UEL4-Lígia e UEL5-Natália, selecionadas no programa de melhoramento genético da Universidade Estadual de Londrina, as quais, nas cinco safras de avaliação, apresentaram produção média de 26 a $30 \mathrm{~kg} /$ planta/ano (CarpentieriPípolo et al., 2002). Embora os dados de produção, isoladamente, não sejam suficientes para definir um genótipo como promissor, devendo estar, ainda, associado a outros descritores de valor de mercado, como a coloração da polpa e da película do fruto e, principalmente, o teor de vitamina $\mathrm{C}$, os genótipos mais produtivos do $\mathrm{BAG}$ poderiam ser considerados promissores quanto a esta característica tendo em vista que, com apenas dois anos de idade, a produção foi acima do valor médio alcançado por aceroleiras de plantios comerciais (3 a 30kg/planta/ ano) (Gonzaga Neto et al., 1999).

Confrontando os dados referentes à massa e à produção dos frutos dos genótipos do BAG, no ano de 2000, evidencia-se que o 013 CPA e o 014-CPA, que foram os mais produtivos, apresentaram frutos pequenos, com massa inferior a $4 \mathrm{~g}$. Fato semelhante foi constatado em 18 genótipos de aceroleira cultivados na região do Submédio São Francisco (Gonzaga Neto et al., 1999)

No período estudado, houve aumento quantitativo no número de frutos/genótipo/ano (Tabela 4), indicando, portanto, que não houve 
estabilização da produção. Esse descritor parece ser menos estável nos três primeiros anos de produção, tendo em vista que marcantes variações referentes ao número de frutos/planta/safra/ano foram observadas no estudo de 18 genótipos de aceroleiras, efetuado no período de 1992 a 1995, por Gonzaga Neto et al. (1999).

Com base nos resultados obtidos, os genótipos 012-CPA, 013CPA e 014-CPA destacaram-se como potencialmente promissores por terem sido os mais produtivos além de terem apresentado características físicas, referentes à massa e ao diâmetro dos frutos, exigidas pelas indústrias de transformação. Entretanto, para lançar variedades comerciais, as características físicas e de produção dos genótipos do BAG/UFRPE devem ser monitoradas por mais tempo, e os genótipos avaliados em outros locais da Zona da Mata de Pernambuco.

\section{REFERÊNCIAS}

BATISTA, F.A.S.; MUGÜET, B.R.R.; BELTRÃOA.E.S. Comportamento e seleção da aceroleira na Paraíba, Fortaleza-CE, 1991. In: CONGRESSO BRASILEIRO DE FRUTICULTURA, 10., 1989. Fortaleza-CE. Anais... Fortaleza: BNB/SBF, 1991.p. 26-32.

CARPENTIERI-PÍPOLO, V.; PRETE, C.E.C.; GONZALEZ, M.G.N.; POPPER, I.O. Novas cultivares de acerola (Malpighia emarginata
D.C.): EUL3- Dominga, UEL4- Lígia e UEL5- Natália. Revista Brasileira de Fruticultura, Jaboticabal, v.24, n.1, p.124-126, 2002.

CRUZ, C.D. Programa GENES: aplicativo computacional em genética e estatística. Viçosa: UFV, 1997. 442p.

EMBRAPA - Centro Nacional de Pesquisa Tecnológica em Informática para Agricultura. SWNTIA, versão 4.2.1. Campinas, 1996.

GONZAGANETO, L.; SOARES, J.M. Acerola para exportação: aspectos técnicos da produção. Brasília: EMBRAPA-SPI, 1994. 43p. (Séries publicações técnicas FRUPEX, 10).

GONZAGA NETO, L.; MATTUZ, B.; SANTOS, C.A.F. Caracterização agronômica de clones de aceroleira (Malpighia spp) na Região do Submédio São Francisco. Revista Brasileira de Fruticultura, Jaboticabal, v.21, n.2, p.110-115, 1999.

GORGATTINETTO,A.;ARDITO, E.F.G.; GARCIA, E.E.C.; BLEINROTH, E.W., FREIRE, F.C.O.; MENEZES, J.B.; BORDIN, M.R.; BRAGA SOBRINHO, R.; ALVES, R.E. Acerola para exportação: procedimentos de colheita e pós-colheita. Brasília: EMBRAPASPI, 1996. 30p. (Série Publicações Técnicas FRUPEX, 21).

IBRAF - INSTITUTO BRASILEIRO DE FRUTAS. Soluções fruta a fruta: acerola. São Paulo: IBRAF, 1995. 59p.

MARINO NETTO, L. Acerola: a cereja tropical. São Paulo: Nobel, 1986. $94 \mathrm{p}$. 